\title{
LOS DIFÍCILES AÑOS CUARENTA PARA EL EXILIO REPUBLICANO DE 1939\&
}

\author{
The tough 1940s for the 1939 Republican Exile
}

\section{Jorge de Hoyos Puente ${ }^{\beta}$}

Fecha de recepción: 21/05/2018 - Fecha de aceptación: 07/10/2018

Resumen. Este artículo explora las principales dificultades que debieron afrontar las organizaciones políticas en el exilio durante la década de los años cuarenta del siglo xx. En ese periodo, los partidos y organizaciones sindicales debieron digerir la derrota republicana y la pérdida de expectativas de un retorno factible a corto plazo. El exilio republicano se vio sometido a tensiones internas y externas que condicionaron su proceso de integración en los países de origen y sus expectativas de regreso a España. Para comprender este proceso, el artículo se centra en la evolución política del exilio en su conjunto, atendiendo a sus principales puntos de fricción durante esta década clave en su devenir histórico. La hipótesis de partida del trabajo trata de mostrar cómo la profunda disparidad de criterios existentes en el seno de las organizaciones a la hora de configurar una respuesta coordinada y unitaria frente al franquismo contribuyó a debilitar las opciones de influir en una acción de lucha eficaz contra la dictadura. Para ello, analizaremos esta pluralidad, así como los factores internacionales que condicionaron la lucha antifranquista desde el exilio en el periodo abordado.

Palabras clave: Exilio republicano; Historia política; Años cuarenta.

Abstract. This paper highlights the main difficulties faced by the Spanish political organizations in exile in the 1940s. Throughout this period, political parties and trade unions had to deal with the Republican defeat and the unlikely perspective of a short-term return. The integration process in the host countries and the possibilities for of a short-term return to Spain were highly

\footnotetext{
\& Este trabajo se inserta dentro del proyecto de investigación «Estado, nación y nacionalización en Europa del Sur y América Latina (1850-1930). Una perspectiva comparada» (HAR2015-64419-P), financiado por el Ministerio de Economía y Competitividad, años 2016-2018.

${ }^{\text {B }}$ Universidad Nacional de Educación a Distancia. Departamento de Historia Contemporánea. C/ Senda del Rey 7, 28040 Madrid. España. jdehoyos@geo.uned.es
}

Cómo citar este artículo: Hoyos Puente, Jorge de. «Los difíciles años cuarenta para el exilio republicano de 1939». Historia y Memoria de la Educación 9 (2019): 25-59. 
conditioned by the internal and external stress to which the Republican exile was subject. In order to understand this process properly, this article focuses on the evolution of the political exile as a whole, addressing the principal conflicts that arose during this key period of its historical transformation. The main premise of the article centers on the broad variety of criteria within the organizations regarding the configuration of a common and unified response to Francoism., This division only weakened any option of achieving an effective combative action against the dictatorship. In addition to analyzing the divergent criteria of the exiles we will also focus on the international factors that affected the anti-Francoist cause during the 1940s.

Keywords: Spanish Republican exile; Political history; The 1940s.

\section{INTRODUCCIÓN}

Los años cuarenta del siglo xx representaron para el exilio republicano una montaña rusa emocional marcada por tres factores fundamentales. En primer lugar, la fractura política que vivieron los exiliados españoles generó una grave crisis institucional, agravada por la dispersión geográfica de sus miembros y las dificultades de todo orden que debieron afrontar en un contexto convulso. En segundo lugar, la consolidación del franquismo como un régimen totalitario, marcado por la represión hacia cualquier tipo de oposición política, aumentó la desprotección de los exiliados declarados enemigos de la patria e imposibilitó cualquier opción de retorno seguro. Finalmente, el complejo desarrollo internacional, condicionado por la evolución de la Segunda Guerra Mundial primero y el surgimiento de la Guerra Fría más tarde, contribuyó a mantener la dictadura y, con ella, la vigencia del exilio. Este artículo explorará estos condicionantes, conectados fuertemente entre sí, desde varios puntos de partida. Por un lado, tratando de evidenciar las raíces de las disputas políticas surgidas de concepciones antagónicas en torno a cómo afrontar la lucha contra el franquismo. Por otro, rastreando los efectos devastadores del final de la guerra y sus consecuencias que contribuyeron a dificultar toda posibilidad de acuerdo debido a los recelos mutuos surgidos dentro y fuera de las organizaciones políticas.

La historiografía sobre el exilio republicano ha crecido de forma exponencial en los últimos años gracias a abundantes y novedosas apor- 
taciones. Esto nos facilitará poder trazar un panorama bastante certero a la hora de afrontar un acercamiento sólido sobre de las dispares circunstancias que los exiliados debieron afrontar en los distintos países de acogida. ${ }^{1}$ Este hecho nos permitirá a lo largo del artículo realizar una difícil labor de síntesis con el objetivo de servir de marco contextual para los trabajos que le suceden dentro del dossier. Para ello, centraremos nuestro relato en la evolución política del exilio republicano.

\section{9-1942: DE LA DERROTA A LA REORGANIZACIÓN: LOS AÑOS DEPRESIVOS}

La derrota republicana al final de la guerra civil abrió un nuevo tiempo político en España que condicionó de forma determinante nuestra historia reciente. Con la imposición por las armas de un régimen totalitario, el franquismo condenó a una parte sustancial de los españoles a ser ciudadanos proscritos por sus ideas políticas, siendo el exilio una forma más de represión. El exilio republicano de 1939, a diferencia de otros exilios precedentes, se caracterizó por su larga duración, por su elevada dimensión numérica, por su dispersión geográfica y por su composición social heterogénea. A estas particularidades es necesario sumar una circunstancia singular: junto con una parte significativa de la población española también se exilió buena parte de las instituciones que conformaron la Segunda República, como fueron los tres poderes del Estado, los gobiernos autonómicos constituidos de Cataluña y Euskadi, así como las organizaciones políticas y sindicales que defendieron la legalidad republicana durante la contienda civil. Por tanto, los exiliados de 1939 contaron con las referencias institucionales y ciertos recursos materiales que se desprendían de ellas para afrontar una difícil situación de inseguridad, inestabilidad e incertidumbre.

Los exiliados compartieron la sensación de miedo, desamparo y depresión frente a la pérdida de toda certeza sobre el futuro inmediato que les deparaba la vida, con independencia de sus diferencias económicas, culturales, generacionales o políticas. A pesar de ello, las experiencias individuales fueron muy dispares. Separaciones familiares forzadas, internamientos en campos de concentración, largas esperas para

\footnotetext{
${ }^{1}$ Jorge de Hoyos Puente, «Los estudios del exilio republicano de 1939 a revisión: una mirada personal», Dictatorships \& Democracies. Journal of History and Culture 5 (2017): 285-312.
} 
conseguir un traslado hacia algún país americano, la escasez de recursos económicos y los problemas de comunicación fueron algunas de las experiencias traumáticas que padecieron los exiliados.

Con el final de la guerra civil se agudizaron muchas de las disputas políticas que generaron fuertes divisiones internas en el bando republicano. ${ }^{2}$ Los dirigentes políticos fueron incapaces de dejar a un lado las acusaciones mutuas en torno a las responsabilidades y las circunstancias de la derrota, aumentando así las tensiones existentes dentro de cada grupo político, que se hallaban divididos entre partidarios y defensores de la dimisión de Manuel Azaña y la posterior sublevación de la Junta de Defensa Nacional de Madrid. La prematura dimisión de Azaña generó una gran incertidumbre en torno a la continuidad de las instituciones republicanas, debilitando las posiciones del gobierno republicano a la hora de actuar en el convulso contexto internacional. A su vez, el golpe de Casado, no solo fue incapaz de conseguir una salida pactada para el final de la guerra, sino que contribuyó a dificultar la evacuación para salvar el mayor número de vidas posibles. ${ }^{3}$ Las circunstancias de la derrota marcaron los debates políticos acerca de la continuidad de las instituciones, cuestionando la raíz misma de uno de los pilares de su fortaleza: la existencia de un Estado en el exilio.

La negativa del presidente de las Cortes, Diego Martínez Barrio, a asumir la presidencia interina de la República contribuyó también a aumentar la incertidumbre sobre la continuidad de las instituciones. Las sesiones de la Diputación Permanente de las Cortes, celebradas en París los días 31 de marzo y 1 de abril de 1939, se convirtieron en la escenificación de un duelo de legitimidades sobre la prevalencia del poder Ejecutivo frente al Legislativo. ${ }^{4}$ Un debate acalorado que enfrentó

\footnotetext{
2 Ángel Viñas y Fernando Hernández Sánchez, El desplome de la República: la verdadera historia del fin de la Guerra Civil (Barcelona: Crítica, 2010); Ángel Bahamonde, Madrid 1939. La conjura del coronel Casado (Madrid: Cátedra, 2014); Paul Preston, El final de la guerra. La última puñalada a la República (Barcelona: Debate, 2014); Francisco Alía Miranda, La agonía de la República. El final de la guerra civil española (1938-1939) (Barcelona: Crítica, 2015).

${ }^{3}$ Abdón Mateos, La batalla de México. Final de la Guerra Civil y ayuda a los refugiados, 1939-1945 (Madrid, Alianza Editorial, 2009): 57.

${ }^{4}$ Enrique Moradiellos ha analizado esta sesión de forma detallada en la biografía que realizó sobre Juan Negrín, Véase Enrique Moradiellos: Negrín, una biografía de la figura más difamada de la España del siglo XX (Barcelona: Península, 2006): 463 y sig. Con todo, el Diario de Sesiones de la Diputación Permanente recoge el contenido de la reunión.
} 
a aquellos que, como Álvaro de Albornoz o el propio Martínez Barrio, consideraban que no podía existir un gobierno sin territorio, frente a la postura de Negrín o del prestigioso jurista y vicepresidente de las Cortes por Izquierda Republicana, Luis Fernández Clérigo, que sostenían que no se daban los requisitos formales para que la Diputación Permanente del Congreso estuviese funcionando fuera de las fronteras. Sin duda, unos y otros afinaron su capacidad dialéctica para tratar de buscar la preeminencia de sus argumentos, en una situación francamente difícil de despejar. Finalmente, el resultado de aquella tensa reunión se saldó con un cierto reforzamiento de las posiciones de Negrín, que abandonó la reunión con el reconocimiento de su papel por parte de la Diputación Permanente, y con la constitución, a instancias de Ramón Lamoneda, de una comisión de seguimiento de la actividad del Servicio de Evacuación de los Refugiados Españoles, el SERE, presidida por Luis Fernández Clérigo. Pero aquella decisión no contentó a todos y se saldó con un sonoro portazo de Luis Araquistain, que presentó su renuncia a pertenecer a la Diputación Permanente en una carta dirigida a Martínez Barrio en calidad de presidente de lo que calificó como «fantasmagóricas Cortes republicanas». ${ }^{5}$ Para una parte importante de los socialistas la posibilidad de que Negrín continuase ejerciendo labores de presidente de gobierno era una realidad difícil de soportar. El tono de crispación y las acusaciones vertidas contra su compañero de partido alcanzaron cotas desconocidas. Contra Negrín confluían dos tendencias del PSOE que hasta el momento no habían coincidido en apenas nada. Por un lado, sectores provenientes del obrerismo largocaballerista que consideraban a Negrín responsable del crecimiento del PCE, y, por otro lado, sectores moderados afines a Prieto que interpretaban la actitud de Negrín como una abierta traición. Unos y otros provenían de universos políticos diferenciados que, sin embargo, encontraron en la demonización de Negrín un punto de unión sobre el que volcar todas las frustraciones y prejuicios.

La proliferación de recelos mutuos y divergencias a lo largo de la guerra, así como los reproches en torno a la responsabilidad en la derrota, fueron elementos medulares que alimentaron un clima de divi-

\footnotetext{
${ }^{5}$ Existe una copia de la carta en el Archivo de Ramón Lamoneda 166-48, sección archivos personales de la Fundación Pablo Iglesias.
} 
sión donde los dirigentes políticos pugnaron por mantener un cierto control político sobre el exilio. El miedo a la pérdida de influencia, o incluso de militancia, jugó un papel central a la hora de buscar alianzas en un clima totalmente diferente. En pocas semanas, los dirigentes políticos pasaron de los ministerios a la precariedad del exilio y, junto a ellos, una parte sustancial de la militancia que podía dejar atrás la horrorosa experiencia de las cárceles franquistas o los campos de concentración franceses. Demasiados cambios en tan poco tiempo, difíciles de asimilar por quienes a duras penas habían logrado adaptarse a los distintos retos que España había experimentado en menos de una década. Aupados al poder desde la clandestinidad en abril de 1931 eran nuevamente expulsados de éste y condenados a un difícil escenario político fuera de España; convertidos de nuevo en partidos proscritos de los que tan sólo la pertenencia era sinónimo de muerte en la España «victoriosa» de 1939.

La confrontación política dentro del exilio aumentó por un hecho fortuito pero central, el control del contenido del yate Vita por parte de Indalecio Prieto en México de forma «accidental». Conocida es la historia del barco y su contenido así cómo los problemas que generó el ansiado cargamento, que estaba destinado por el gobierno Negrín al sostenimiento de las instituciones republicanas fuera de España y la ayuda a los republicanos en el exilio. ${ }^{6}$ El control del barco por Indalecio Prieto favoreció el enfrentamiento definitivo con Juan Negrín, fracturando al PSOE primero, y al conjunto del exilio más tarde, de forma definitiva. La pugna por el control de los recursos económicos ahondó el clima de crispación existente y generó duplicidades en torno a la gestión de las ayudas a los exiliados.

En julio de 1939 las tesis de Prieto se impusieron en una nueva reunión de la Diputación Permanente de las Cortes en París, donde se de-

\footnotetext{
${ }^{6}$ A este respecto véase Amaro del Rosal, El oro del banco de España y la Historia del Vita (Barcelona: Grijalbo, 1976); Virgilio Botella Pastor, Entre memorias, las finanzas del gobierno republicano español en el exilio (Sevilla: Biblioteca del Exilio, 2002); Ángel Herrerín, El dinero del exilio, Indalecio Prieto y las pugnas de posguerra (1939-1947) (Madrid: Siglo XXI, 2007); Pedro Luis Angosto, La República en México, con plomo en las alas, 1939-1945 (Sevilla: Renacimiento, 2009); Francisco Gracia Alonso y Gloria Munilla, El tesoro del «Vita». La protección y el expolio del patrimonio histórico-arqueológico durante la Guerra Civil (Barcelona: Universitat de Barcelona, 2013): Aurelio Velázquez, Empresas y finanzas del exilio. Los organismos de ayuda a los republicanos españoles en México (1939-1949) (México: El Colegio de México, 2014).
} 
cidió desconocer la existencia del gobierno presidido por Negrín y la constitución de una Junta de Auxilio a los Republicanos Españoles para gestionar esos fondos, supervisada por la Diputación Permanente que se trasladaría a México para tal fin. Estas medidas representaron una extralimitación de las atribuciones que legalmente tenía asignada la Diputación Permanente. Historiadores como Hartmut Heine o Ricardo Miralles sostienen que se trató de una extralimitación y un error político evidente. ${ }^{7}$ Con todo, la decisión fue llevada adelante, privando al exilio de una autoridad clara. Sin embargo, Negrín no se dio por vencido, y pese a que su posición salió de aquella reunión francamente debilitada, no aceptó el resultado de la votación, alegando falta de competencias de la Diputación para tomar aquella decisión trascendental. A pesar de los apoyos cosechados por Prieto dentro y fuera del PSOE, Negrín contaba aún con algunas bazas importantes, ya que conservaba intacto el apoyo de la Ejecutiva socialista, presidida por el líder asturiano Ramón González Peña, ministro en su gobierno, y del tipógrafo andaluz Ramón Lamoneda, que ejercía las funciones de secretario general del PSOE. Si Prieto controlaba los fondos del Vita, Negrín mantenía todavía algunos recursos dispersos en distintas cuentas a nombre de sus colaboradores más fieles. Por todo ello, se creó una duplicidad de instituciones de ayuda a los refugiados que fueron determinantes a la hora de establecer núcleos de poder e influencia dentro de las organizaciones exiliadas, especialmente en América.

La gestión de los recursos a través del Servicio de Evacuación de Refugiados Españoles, el SERE, controlado por Negrín, y de la Junta de Auxilio a los Republicanos Españoles, la JARE, controlada por Prieto, generó más divisiones. Acusaciones mutuas de mala gestión, de unos recursos claramente insuficientes, contribuyeron a aumentar la brecha entre los dirigentes políticos y sus bases, que padecían las penurias de los campos de concentración y la incertidumbre ante un posible traslado hacia América. No pocos exiliados veían con incredulidad la inquina de los debates internos y la falta de estrategias coherentes y unitarias que centraran los esfuerzos en paliar el sufrimiento del pueblo español dentro y fuera del país.

\footnotetext{
${ }^{7}$ Hartmut Heine, La oposición política al franquismo (Barcelona: Crítica, 1983): 30; Ricardo Miralles, Juan Negrín, La República en guerra (Madrid: Temas de hoy, 2003): 336-337.
} 
Las organizaciones políticas emprendieron pronto el proceso de reorganización de sus estructuras. La dispersión de los militantes junto a la falta de referencias e informaciones claras fortaleció el papel de los líderes políticos frente a las bases que, a su vez, trataban de establecer pequeñas células en condiciones tan precarias como las de los campos de concentración. Con el traslado de los principales dirigentes a México, este país se convirtió en el centro más importante de la vida política del exilio, tanto por la relativa libertad de acción de la que gozaron las organizaciones políticas, como por la progresiva llegada de exiliados a sus tierras.

Sin duda, el delicado contexto internacional generó nuevas preocupaciones por el clima prebélico que se vislumbraba de forma inminente en el continente europeo. La firma del pacto Ribbentrop-Molotov en agosto de 1939 supuso un duro golpe en las filas de aquellos que consideraban a la Unión Soviética como la única esperanza ante el auge del fascismo en Europa. Para muchos comunistas que habían combatido al fascismo en España, la firma de un pacto de no agresión entre la Unión Soviética y la Alemania de Hitler era inaceptable. Este fue el caso de Miguel Serra Pamiés, destacado dirigente del PSUC, que se separó del partido ante el estupor creado por la firma del pacto Germano-Soviético. ${ }^{8}$ Otros dirigentes del PSUC, como Fábrega, Ferrandis, Fabregat y Palerm Vich abandonaron el partido a causa del pacto. ${ }^{9}$ Aquel acuerdo contra natura abonaba el campo de las tesis anticomunistas dentro del exilio y dividía las filas del PCE aislándolo del grueso del exilio.

En ese clima de fragmentación existente y ante la falta de referentes institucionales consensuados, la reorganización de los distintos partidos políticos se convirtió en una tarea inexcusable. Pese a las críticas vertidas contra el SERE por la supuesta selección realizada, siguiendo criterios ideológicos, lo cierto es que durante los meses de verano y otoño de 1939 habían llegado a México cuadros de todas las organizaciones políticas. Como lugar de encuentro político funcionó el Centro Republicano Español, fundado el 27 de marzo de 1939 en los antiguos locales del Consulado español en la calle Balderas número 37 de la ciudad de México. Allí se dieron citas republicanos, socialistas, nacionalistas e in-

\footnotetext{
${ }^{8}$ Fondo IPS, Archivo General de la Nacional (México) Caja 69, exp. 3, folios 62-63.

9 Joan Estruch, El PCE en la clandestinidad, 1939-1956 (Madrid: Siglo XXI, 1982): 35.
} 
cluso anarcosindicalistas, todos, salvo los comunistas, que fueron vetados. ${ }^{10}$ En sus distintos espacios se fueron configurando pequeñas oficinas de las organizaciones a través de las cuales los refugiados podían ir «normalizando» su participación política. Ante la imposibilidad de funcionar con los nombres de los partidos políticos en México, las organizaciones recurrieron a tapaderas de tinte cultural para mantener su actividad. Así, se fueron creando el Ateneo Salmerón, correspondiente con Izquierda Republicana, el Ateneo Pi y Margall, que aglutinó a los republicanos federales, o el Círculo Cultural Pablo Iglesias, donde ingresaban los socialistas a su llegada a México. ${ }^{11}$

El estallido de la Segunda Guerra Mundial en Europa marcó la vida del exilio republicano complicando los ansiados traslados hacia América. Mientras muchos españoles continuaban hacinados en pésimas condiciones en campos franceses o eran destinados a los batallones de trabajadores y se alistaban para continuar luchando por la democracia y la libertad, los partidos políticos continuaban en un proceso de cuestionamiento interno y desintegración. ${ }^{12}$ Desde comienzos de 1940 hasta finales de 1942, la actividad política pivotó sobre dos ejes básicos. Por un lado, la lucha por el control del discurso del exilio desde diferentes posiciones, partiendo de una lectura compartida de la realidad que consideraba al exilio como único portavoz autorizado para hablar en nombre de una España secuestrada por la dictadura. Por otro lado, los intentos infructuosos por mantener la unidad dentro de las organizaciones políticas que se resquebrajaban internamente ante la disparidad de criterios esgrimidos por sus líderes.

Sin duda, la fractura dentro del PSOE fue la más relevante y compleja. Los militantes quedaron divididos no solo por la pugna entre Prieto y Negrín, sino también por dos concepciones antagónicas sobre el papel del partido durante la Segunda República y su proyección de futuro, generando estructuras paralelas que se arrogaban la representación legítima del partido y de su organización sindical hermana,

\footnotetext{
${ }^{10}$ Alicia Alted, La voz de los vencidos. El exilio republicano de 1939 (Madrid: Aguilar, 2005): 241.

${ }_{11}$ Jorge de Hoyos Puente, La utopía del regreso. Proyectos de Estado y Sueños de Nación en el exilio republicano en México (México: El Colegio de México, 2012): 91-119.

12 Guadalupe Adámez Castro, Gritos de papel. Las cartas de súplica del exilio español (Granada: Comares, 2017); Diego Gaspar Celaya, La Guerra continúa. Voluntarios españoles al servicio de la Francia Libre (1940-1945) (Madrid: Marcial Pons, 2015).
} 
la UGT. Los partidos republicanos vivieron un proceso diferente. Mermada su militancia durante la guerra, Izquierda Republicana y Unión Republicana, sus organizaciones más representativas, afrontaron los primeros tiempos exhaustos y desorientados por la dimisión de Manuel Azaña y la inhibición institucional de Martínez Barrio. La concepción reformista de los republicanos liberales había quedado totalmente destruida durante la guerra. La única salida viable que encontraron fue la búsqueda de una cierta unidad de acción entre ellos a través de la constitución de Acción Republicana Española, una plataforma conjunta creada en México el 14 de abril de $1940 .{ }^{13}$ Los republicanos cayeron mayoritariamente en una paradoja singular: al mismo tiempo que defendían la continuidad de la legalidad republicana, negaban la existencia del gobierno en el exilio que presidía Juan Negrín.

La situación del anarcosindicalismo no era mucho más halagüeña. ${ }^{14}$ Muy divididos internamente por la estrategia desplegada durante la guerra, las distintas sensibilidades vivieron un proceso maximalista que favoreció las rupturas y divisiones a medio y largo plazo. La mayoría de las disputas se centraron en el terreno de las tácticas, entre los partidarios de volver a las esencias y los defensores de colaborar con las organizaciones políticas como mejor estrategia para luchar contra el franquismo. ${ }^{15}$ Francia y México se convirtieron en los dos países con mayor número de anarcosindicalistas españoles, siendo Toulouse la capital del exilio libertario.

El PCE, con sus principales dirigentes en la Unión Soviética, tuvo que hacer frente a una crisis importante entre sus bases tras la publicación del pacto de no agresión germano-soviético. Aislado del resto de organizaciones del exilio, su discurso estaba condicionado a los cambios de política de la Unión Soviética, teniendo que defender el pacto como un mecanismo de salvaguarda de la revolución bolchevique frente al imperialismo capitalista de las potencias occidentales. La invasión alemana de la Unión Soviética en junio de 1941 cambió radicalmente el

\footnotetext{
13 Ángel Duarte, El otoño de un ideal. El republicanismo histórico español y su declive en el exilio de 1939 (Madrid: Alianza Editorial, 2009).

14 Ángel Herrerín, La CNT durante el franquismo. Clandestinidad y exilio (1939-1975) (Madrid: Siglo XXI, 2004); Alicia Alted y Lucienne Domergue, La cultura del exilio anarcosindicalista español en el sur de Francia (Madrid: Ediciones cinca, 2012).

15 Fidel Miró, Anarquismo y anarquistas (México: Editores Mexicanos Unidos, 1979): 129 y sig.
} 
discurso del PCE, optando por buscar un acercamiento a las organizaciones del exilio.

Ante este estado de cosas, dentro del campo de los defensores de la República, los grupos nacionalistas vasco y catalán optaron por sondear la posibilidad de salidas unilaterales dentro de un contexto internacional revuelto. En 1940, desde Londres y en nombre de los creados Consejos Nacional de Cataluña y Consejo Nacional de Euskadi, se exploró la posibilidad de alcanzar la independencia con apoyo de las autoridades británicas, llegando a redactarse un anteproyecto de constitución para la República vasca, lo que generó el rechazo unánime por parte del resto de organizaciones políticas exiliadas. ${ }^{16}$

Ante este lóbrego panorama, bien podemos afirmar que los primeros años del exilio fueron años de desconcierto y desafección ante la falta de un rumbo claro y un discurso nítido que situase a los exiliados y sus expectativas en una posición útil. La prolongación de los enfrentamientos y la deslegitimación del gobierno generaron un proceso depresivo de disgregación política, donde la mayoría de los exiliados debían, a su vez, tratar de reconstruir sus vidas ante un horizonte incierto en el que las esperanzas de regresar se mantenían con pocas bases empíricas sobre las que cimentar ese deseo. Mientras, el franquismo se consolidaba a través de la construcción de un nuevo Estado sustentado en la represión y la arbitrariedad.

\section{LAS RAZONES DE LAS DISPUTAS: PROYECTOS CONTRAPUESTOS PARA ESPAÑA}

La coyuntura internacional condicionó de forma trascendental la agenda política y las expectativas de un posible regreso a España. Después de un periodo de lento acomodo a una nueva realidad política, pero también vital, el exilio, en su conjunto, experimentó a partir de 1942 un proceso de reorganización de sus proyectos de futuro para la liberación y la reconstrucción de España. La mundialización de la guerra europea con la participación de la URSS y los Estados Unidos, pero también con la presencia de la División Azul junto a las potencias del

\footnotetext{
16 Juan Carlos Jiménez de Aberasturi, «Irujo en Londres, 1939-1945», Vasconia: Cuadernos de historia-geografía 32 (2002): 99-132.
} 
Eje, parecía ilustrar de forma nítida la tesis defendida por los exiliados españoles sobre la existencia de la alianza entre Franco y Hitler que ya no podían negar los aliados. De este modo, los republicanos consideraron inevitable su caída si se producía una victoria aliada frente al nazi-fascismo internacional. Ante este estado de cosas, era necesario organizarse para regresar a una España liberada de la tiranía en condiciones óptimas. Aquellos acontecimientos produjeron un cambio de lenguaje en las organizaciones políticas del exilio, un inevitable reacomodo de los discursos a un nuevo escenario político que hacía necesario reavivar la causa de los derrotados en la guerra civil ante las potencias aliadas.

El exilio en su conjunto se movió en los años de la esperanza en dos terrenos complementarios, desplegados muchas veces desde posiciones antagónicas. En primer lugar, la definición de proyectos de Estado para la España del futuro, propuestas que se originaron desde diferentes organizaciones y en gran medida incompatibles entre sí. En segundo lugar, la formulación de estrategias que llevaran a cabo de forma más eficaz la puesta en marcha de estos proyectos. Estas estrategias se articularon en función de la pugna por la hegemonía del exilio, como veremos a continuación.

En el terreno de los proyectos de futuro para la reconstrucción de España hay que señalar varias cuestiones importantes. En primer lugar, aunque existieron al menos cinco grandes proyectos fueron dos los que resultaron más competitivos en términos de hegemonía social dentro del exilio, siendo aquéllos los que se organizaron en torno a una salida restauradora de la República por un lado y, por el otro, el que optó por abrir las opciones hacia una solución plebiscitaria que definiera un nuevo marco político para España. En segundo lugar, cabe resaltar la incompatibilidad entre ambos en la medida en que, si bien, el primero fundamentaba su afán restaurador en la defensa de la vigencia de las instituciones republicanas en el exilio, el segundo las consideraba un lastre a la hora de poder influir eficazmente en las potencias aliadas. Finalmente, es necesario subrayar un elemento central a la hora de poner en marcha estos proyectos políticos y es la falta de una estrategia clara para derrotar y desalojar del poder al franquismo. Este último factor estuvo condicionado por la firme creencia, compartida de forma unánime por todo el exilio, en la insostenibilidad de la dictadura en España sin el apoyo de Alemania e Italia. Todo el exilio en su conjunto abrazó la 
causa de las potencias aliadas como la suya propia, sin olvidar los agravios recibidos durante la guerra española, conceptualizada, ya sí, como la primera parte del desarrollo de la Segunda Guerra Mundial.

Conviene resumir brevemente estos proyectos de Estado para comprender la disparidad de criterios que existía dentro del exilio republicano, y que son la base de no pocos de los desencuentros que se habían generado en el inmediato pasado y durante toda la década que estamos estudiando. En primer lugar, el proyecto legitimista, que sustentaron los partidos republicanos, partía de la firme convicción de que el Estado franquista no podía ser considerado un sustituto legítimo de la Segunda República, ya que ésta emanaba de la voluntad popular y continuaba vigente en el exilio. Todas las actuaciones del Estado franquista debían ser condenadas y perseguidas, en la medida en que sus acciones habían puesto los recursos del país y a sus ciudadanos al servicio de intereses extranjeros, como pago por el apoyo prestado durante la contienda civil que había condicionado de forma determinante la victoria militar franquista. Para hacer visible y reforzar esa legitimidad institucional en el exilio era necesario reordenar las instituciones republicanas, constituyendo un gobierno provisional fuerte con el mayor apoyo político posible, para afrontar los difíciles problemas que el franquismo estaba generando. ${ }^{17} \mathrm{El}$ proyecto legitimista rechazaba repetir fórmulas como las del Frente Popular que habían desplazado a la República del eje central donde pretendían situarla. La República debía aprender de los errores del pasado para no repetirlos, centrando sus esfuerzos en crear un Estado y una administración eficaz, capaz de dar soluciones eficaces a los problemas económicos y sociales que arrastraba el país.

El proyecto de los republicanos liberales apostaba por la restauración constitucional como primer paso para recuperar las libertades antes de afrontar reformas legales que corrigiesen errores y deficiencias en la organización económica, social y territorial del país. Una república federal que no cuestionase la unidad de España y que garantizase la igualdad de los ciudadanos ante la ley. Una república intervencionista en materia económica, capaz de combinar la iniciativa privada con la corrección de desigualdades a través de la política fiscal y laboral. Una república, finalmente, que garantizase la plena libertad de los

\footnotetext{
17 Diego Martínez Barrio, Discurso en el Centro Español (México: A. Artis impresor, 1942): 11-12.
} 
ciudadanos, comenzando por la libertad de conciencia y que construyera, a través de la enseñanza, competencia única del Estado, un nuevo marco de relaciones sociales entre los españoles.

El proyecto plebiscitario surgió de Indalecio Prieto y su entorno dentro del partido socialista. ${ }^{18}$ Su visión crítica con la deriva de la República y el papel del PSOE les llevó a rechazar acciones como la revolución de octubre de 1934 y la política frentepopulista. En el famoso discurso pronunciado el primero de mayo de 1942 en el Círculo Pablo Iglesias, Prieto esbozó, a modo de confesiones y rectificaciones, su percepción de la situación del momento, así como las lecciones aprendidas en los últimos años. Su concepción de socialismo iba asociado a una defensa inquebrantable de los principios liberales, consolidados en un régimen democrático. ${ }^{19} \mathrm{El}$ socialismo debía aprender de sus errores y supeditar algunas de sus aspiraciones y tácticas políticas al respeto de la legalidad democrática. De ahí su crítica al papel jugado por los sindicatos a lo largo de la Segunda República. A su juicio, en el futuro, los sindicatos deberían actuar de forma leal con el Estado, relegando sus intereses de clase frente al interés general. Ni las tácticas revolucionarias, ni los intereses sindicales podían hacer tambalear a un Estado democrático. Para Prieto, sólo desde el Estado democrático, a través de las reformas estructurales necesarias, podían los obreros alcanzar el nivel de bienestar y derechos que en justicia les correspondía.

Desde su salida de España y tras el dramático final de la guerra, Prieto, como muchos otros socialistas de la talla de Largo Caballero o Luis Araquistain, dieron por muertas las instituciones republicanas. ${ }^{20}$ Los socialistas liderados por Prieto fueron los primeros en pretender abrir un nuevo tiempo político donde el pueblo decidiera su destino a través de plebiscitos. Las urnas debían decidir si los españoles querían

\footnotetext{
18 José Carlos Gibaja, Indalecio Prieto y el socialismo español (Madrid: Editorial Pablo Iglesias, 1995); Ricardo Miralles (ed.), Textos escogidos, Indalecio Prieto (Oviedo: Junta General del Principado de Asturias, 2002); Octavio Cabezas, Indalecio Prieto. Socialista y Español (Madrid: Algaba, 2005); Abdón Mateos (ed.), Indalecio Prieto y la política española (Madrid: Fundación Pablo Iglesias, 2008).

${ }^{19}$ Indalecio Prieto, Confesiones y rectificaciones (México: Círculo Pablo Iglesias, 1942): 14.

${ }^{20}$ Araquistain lo hizo mediante su dimisión de la Diputación Permanente y Largo a través de su "Carta a un obrero», escrita en el Cuartel General de la Comandancia del Ejército Ruso de Ocupación en Berlín, el 1 de agosto de 1945, tras ser liberado del campo de concentración de Sachsenhausen-Oranienburg.
} 
monarquía o república. ${ }^{21}$ La apuesta de los socialistas sería la república, pero acatarían el resultado de las urnas, no considerando la opción monárquica inviable. Para el socialismo prietista era imprescindible establecer un nuevo marco político en España contando con una derecha democrática y civilizada, que permitiese y ejerciese la representación de una parte importante de la sociedad.

El nuevo Estado debía dotarse de un poder ejecutivo fuerte capaz de llevar a cabo las reformas económicas necesarias, respetando la propiedad privada, para mejorar la vida de los españoles. Un Estado descentralizado administrativamente, sin necesidad de recurrir a salidas federales, capaz de generar una dinámica reformista que integrase a sectores conservadores comprometidos con principios liberal-democráticos.

Si estos dos proyectos de Estado fueron los más seguidos, no podemos obviar otras visiones que tuvieron su relevancia a la hora de establecer alianzas con los dos anteriores, basculando y condicionando la viabilidad de los mismos. El tercer proyecto de Estado fue el articulado en torno al obrerismo marxista, que abarcó a diferentes sectores del exilio procedentes en su mayoría del PCE, el PSUC y parte del PSOE. Fundamentado en torno a la noción de clase, este proyecto de Estado basaba su legitimidad en el establecimiento de una lectura equivalente de la idea de "clase» y de "pueblo», y explicaba el surgimiento y evolución de la Segunda República como una «República Popular». En ese sentido, se diferencia claramente de los dos proyectos anteriores en su firme defensa de la estrategia del Frente Popular como el mecanismo útil para la recuperación de la República en España. La reivindicación de la lucha obrera y del papel de la militancia organizada resultaba capital permitiéndoles conectar más fácilmente con los que permanecían luchando en la clandestinidad y la resistencia dentro de España. El principal problema de este discurso, que conectaba con amplios sectores populares del exilio que habían protagonizado la lucha social durante la República y la guerra, era cómo articular un proyecto de República popular que no cayera en esquemas demasiado supeditados a la URSS y favoreciera alianzas más allá de un PCE controlado por Moscú.

\footnotetext{
${ }^{21}$ Indalecio Prieto, Posibilidades de convivencia pacífica en España. Discurso pronunciado en los actos del Primero de mayo de 1947 en México (Buenos Aires: PSOE, 1947): 31.
} 
Así, el proyecto se movió en una cierta indefinición de una República popular fuerte que controlase los principales medios de producción respetando las nacionalidades existentes dentro de España, permitiendo al PSUC defender la Unión de Repúblicas Socialistas en España. ${ }^{22}$

Esta propuesta se fue modificando y suavizando en la medida en que las circunstancias fueron cambiando, incluyendo claras referencias democráticas y de independencia nacional, diferenciando «clase» y «pueblo» e introduciendo conceptos como «nación española» o "patria». ${ }^{23}$ Estos cambios trataron de favorecer el acercamiento a los sectores obreristas del socialismo y la UGT, partidarios de la continuidad del gobierno Negrín, al que los comunistas de forma intermitente apoyaron en estos años de exilio.

El cuarto proyecto de Estado surgió desde las bases del nacionalismo catalán, vasco y, en menor medida, gallego. Estos grupos partían de una concepción de Cataluña, Euskadi y Galicia como naciones plenas, con soberanía propia, que debía ser reconocida y respetada. Con la desaparición de la República, los nacionalistas optaron en un primer momento por dar por finalizados los gobiernos autonómicos y apostaron por articular salidas unilaterales buscando un reconocimiento propio en el marco europeo. ${ }^{24}$ Fracasado este primer intento, no compartido por todos, surgieron voces como la de Bosch Gimpera, para defender una Commonwealth de naciones, de naturaleza confederal, que permitiese el libre desarrollo de las diferentes naciones existentes dentro de España. Lo cierto es que los distintos grupos nacionalistas formularon la continuidad del pacto Galeuzca, alianza forjada durante la Segunda República como mecanismo de solidaridad y apoyo mutuo con el horizonte final de la independencia como objetivo a largo plazo. ${ }^{25}$ En Londres, a instancias de Manuel de Irujo y Carles Pi Sunyer, se pro-

\footnotetext{
22 Joan Comorera, El problema de les nacionalitats a Espanya (México: PSUC, 1942).

${ }^{23}$ Véase el texto publicado a propósito de la celebración del Primero de mayo de 1942, donde clase y pueblo comienzan a tratarse de forma diferenciada, en España Popular (México) 90, 1 de mayo de 1942: 6. El texto comienza con «Para la clase obrera y el pueblo español este Primero de mayo de 1942 debe significar ante todo una profunda intensificación de su lucha».

${ }^{24}$ Santiago de Pablo y Ludger Mees, El péndulo patriótico, historia del Partido Nacionalista Vasco, 1895-2005 (Barcelona: Crítica, 2005).

${ }_{25}$ Xosé Estévez (ed.), Antología de Galeuzca en el exilio, 1939-1960 (San Sebastián: J.A. Ascunce, 1992).
} 
dujo en 1945 una serie de reuniones con el exiliado portugués Armando Cortesão y con Luis Araquistain, que dieron origen a la denominada $\mathrm{Co}$ misión de la Comunidad de Naciones Ibéricas, un intento de configurar un entre supranacional que, de forma confederal, vertebrase una República capaz de sustituir a las dictaduras de Franco y Salazar. ${ }^{26}$ Los nacionalistas recurrían a la opción ibérica no tanto por convicción, sino como un intento por neutralizar el peso de «Castilla» frente a sus reivindicaciones. Después de estos intentos, condenados al fracaso, su discurso fue retornando a la defensa de los gobiernos autonómicos.

Finalmente, el quinto proyecto de futuro para España se articuló desde el obrerismo libertario. Por su propia concepción, resulta problemático calificarlo de proyecto de Estado, sin embargo, en la formulación libertaria el papel del Estado está presente, partiendo de una creencia firmemente compartida en sus filas; fuese cual fuese el resultado de la guerra mundial, los Estados futuros se articularían de forma diferente. ${ }^{27}$ La defensa de la autonomía del individuo frente al Estado, del municipalismo asambleario y del cooperativismo eran las bases sobre las que el obrerismo libertario pretendía fundamentar la sociedad futura.

Como podemos comprobar con este breve repaso a los proyectos de futuro para la España democrática, concebidos desde el exilio, existía una pluralidad de enfoques incompatibles entre sí que estuvieron en la base de los desencuentros duraderos acerca de cómo afrontar la reconstrucción del país. Alejados de la situación que se vivía dentro del país, los exiliados formularon sus utopías desde concepciones opuestas que marcaron la evolución política de la oposición antifranquista en el exilio. Sin tener en cuenta esta pluralidad, difícilmente podemos entender la evolución de las estrategias desplegadas durante los años de la esperanza por parte de las diversas organizaciones políticas, de las que nos ocuparemos a continuación.

\footnotetext{
${ }^{26}$ La síntesis del proyecto se puede leer en Jaume Miravilles, «Pasado y futuro de la Península Ibérica», Galeuzca 9 (Buenos Aires) (1946): 395 y sig. Armando Cortesão, Luis Araquistain, Manuel de Irujo y Carles Pi Sunyer, La Comunidad Ibérica de Naciones (Buenos Aires: Exin, 1945); Luis Monferrer, Odisea en Albión: los republicanos españoles exiliados en Gran Bretaña, 1939-1977 (Madrid: Ediciones de la Torre, 2008): 223 y sig.

27 «Preocupaciones inevitables: el triunfo de las democracias y el proletariado», CNT (México) 8, 1 de octubre de 1943: 1.
} 


\section{2-1947 DE LA REORGANIZACIÓN AL COLAPSO: LOS AÑOS DE LA ESPERANZA}

Desde mediados de 1942 las distintas organizaciones políticas presentes en el exilio trataron de cambiar la dinámica centrífuga y autodestructiva por otra más propositiva e inclusiva. Este cambio fue motivado, en gran medida, por una coyuntura internacional, más propicia para la causa republicana, y por una cierta estabilización material y espacial de los diferentes contingentes de españoles que, distribuidos por el mundo, configuraban el grueso del exilio republicano. México se convirtió en el centro de la vida política del exilio, en parte gracias a la libertad de movimientos de que gozaron las organizaciones políticas, aunque no faltaron aportaciones e iniciativas desde otros centros geográficos como fueron Londres, Buenos Aires, La Habana, Moscú, Toulouse o, en menor medida, Nueva York. Comenzaba la etapa de mayor efervescencia política de todo el exilio, los años de la esperanza, donde los distintos grupos pugnaron por imponer su visión de futuro y acomodaron sus estrategias y tácticas a una coyuntura volátil.

La primera de las tareas emprendidas fue la de reconciliar a las organizaciones políticas con sus antiguas bases. Después de años de un cierto abandono y desmoralización era necesario volver a ilusionar a los militantes y tratar de atraer al mayor número posible mediante actos de movilización. En ese sentido, cabe destacar que el PCE sobresalió en un intento de recuperar a los desencantados con el pacto germano-soviético gracias al cambio de coyuntura internacional y, a su vez, atraerse a sectores del nacionalismo a través de la defensa del derecho de autodeterminación en las denominadas «Alianzas nacionales». ${ }^{28}$ El PCE buscó con insistencia conquistar a amplios sectores del exilio, priorizando a los partidarios de las tesis de Negrín, existentes en todas las ideologías.

Esta estrategia expansionista fue compartida también por los partidos republicanos y los socialistas reformistas que buscaron movilizar a los exiliados más jóvenes y contrarrestar la acción de las Juventudes Socialistas Unificadas, controladas por el PCE. Cercanos a las posturas de los partidos republicanos surgieron grupos de naturaleza corpo-

\footnotetext{
${ }^{28}$ Pablo Carrión, «La delegación del PCE en México 1939-1956, origen y límite de una voluntad de liderazgo de la oposición», Espacio, Tiempo y Forma, Serie V,no. 16 (2004): 309-336.
} 
rativa como la Asociación de Militares Españoles leales a la República, que consiguió aglutinar a más de setecientos oficiales del ejército republicano bajo la reclamación de unidad de acción política, respeto a la legislación republicana, defensa de los principios democráticos y neutralidad de los militares en la acción partidista. ${ }^{29}$

Pronto se puso de manifiesto que el fortalecimiento de las organizaciones políticas tenía un desarrollo limitado y era necesario iniciar una política de alianzas entre distintos grupos. Así nació la Unión Democrática Española, la UDE, promovida por el PCE, que aglutinó a los distintos sectores que apoyaban a Negrín dentro del PSOE y la UGT, pero también a republicanos liberales como Antonio Velao, Luis Fernández Clérigo o Elfidio Alonso, defensores de la legitimidad de la continuidad del gobierno Negrín. ${ }^{30}$ La UDE proclamó la continuidad del aparato institucional completo del Estado republicano en el exilio y su alineamiento claro con las potencias aliadas que luchaban por derrotar el mismo totalitarismo que se había impuesto en España a través de la figura de Franco. La UDE entraba en clara competencia con la posición legitimista de los partidos republicanos que no tardaron en utilizar su plataforma unitaria, ARE, para atacar esta iniciativa. Desde ARE se criticó la pretensión de la UDE de mantener vivo el espíritu del Frente Popular y el reconocimiento al gobierno Negrín, ya enterrado por la Diputación Permanente de las Cortes en julio de 1939. ${ }^{31}$

A finales de 1942 comenzaron a vislumbrarse las tres salidas articuladas desde los tres proyectos políticos antagónicos. Para los republicanos liberales, el camino a seguir era trabajar en la senda de crear las condiciones legales necesarias para reunir las Cortes y nombrar un

\footnotetext{
${ }^{29}$ Declaración fechada el 16 de diciembre de 1943. Existe una copia del manifiesto en el Archivo de Amaro del Rosal, 357-3, folios 166-167, Fundación Pablo Iglesias. La asociación de militares editó a partir de julio de 1943 un Boletín de la asociación de militares profesionales leales a la República española, dedicado al análisis de la guerra. Se conserva un ejemplar en la Fundación Pablo Iglesias, Sig. P. 476.

${ }^{30}$ UDE fue creada el 16 de febrero de 1942, conmemorando así el aniversario del triunfo electoral del Frente Popular; véase Heine, La oposición política al franquismo: 107. En el Archivo del Ateneo Español de México existe documentación que demuestra que UDE recibió de forma regular importantes cantidades de dinero procedentes del Doctor José Puche. Véase «Resumen General de Estado de Cuentas de Unión Democrática Española desde su constitución hasta junio de 1943, fecha en que se disuelve dicho organismo» en el citado archivo, 43.415. folios 1-6.

${ }^{31}$ Circular n. ${ }^{\circ} 39$ de la Junta Central de ARE, fechada en México el 30 de julio de 1942. Fondo Carlos Esplá 5.2/5118-a. Centro Documental de la Memoria Histórica, Salamanca.
} 
nuevo gobierno en el exilio; mientras, el obrerismo marxista y sus aliados en torno a UDE defendieron la plena legalidad del gobierno Negrín como voz autorizada para hablar en nombre de la España democrática y aglutinar en torno a sí al exilio. Por último, la opción defendida por Prieto era convocar un plebiscito para que el pueblo español decidiese libremente la forma de gobierno más adecuada entre monarquía o república, idea que ya había propuesto en 1939 y que comenzaba a concretarse como un posible acercamiento hacia sectores conservadores liberales. ${ }^{32}$ La posición política de Prieto se vio súbitamente debilitada en noviembre de 1942 cuando el gobierno mexicano declaró la intervención económica de la JARE ante las sospechas existentes en torno a su gestión. ${ }^{33}$

1943 fue un año clave en la vida política del exilio republicano. Por un lado, los pasos dados por el régimen franquista para su consolidación institucional, como fue la puesta en funcionamiento en marzo de las Cortes Españolas, convencieron a muchos dirigentes políticos de la necesidad de reactivar las Cortes republicanas en el exilio como primer paso para reorganizar la representación política de la España democrática. Por otro lado, se extendió la idea de ensanchar las bases de la oposición al franquismo recurriendo a monárquicos y conservadores desencantados. Esta postura se hizo ampliamente visible en el PCE en Francia que exploró a través de la Unión Nacional Española (UNE) y la Junta Suprema el establecimiento de relaciones con desencantados del interior, generando tensiones con el PCE de México por su estrategia de apoyo al gobierno Negrín. ${ }^{34}$ La Junta Suprema apelaba al desencanto de sectores conservadores, excluidos dentro del régimen, que consideraban a Franco un testaferro de los intereses extranjeros en España. Estos grupos, movidos por patriotismo, estaban dispuestos a salvaguardar la independencia del país y debían ser tenidos en cuenta como parte del antifranquismo. La Junta Suprema, tutelada por el PCE, defendió la lucha armada en el interior a través de tácticas revolucionarias, restando importancia a las acciones en el exterior, circunscritas a propor-

\footnotetext{
32 Según Octavio Cabezas, Prieto formuló la tesis del plebiscito en la conferencia que pronunció en el Ateneo de Montevideo el 20 de enero de 1939; véase Cabezas, Indalecio Prieto, 498.

${ }^{33}$ Herrerín, El dinero del exilio.

${ }^{34}$ Discurso de Vicente Uribe ante el Sindicato de electricistas de México el 6 de febrero de 1943; Vicente Uribe, Qué es y qué representa la Unión Nacional de los Españoles (México: PCE, 1943).
} 
cionar apoyo logístico y propagandístico. Con una cierta reivindicación de los procesos de juntas locales y provinciales que dieron origen a la lucha durante la invasión napoleónica, el horizonte final era la constitución de un gobierno provisional que liderara el derrocamiento del franquismo y posteriormente abriera un periodo constituyente..$^{35}$

La defensa por parte del PCE de esta estrategia, que culminaría con el fracaso de la invasión guerrillera del Valle de Arán en octubre de 1944, no consiguió sus objetivos de atraer a un número significativo de conservadores a sus tesis y, sin embargo, alejó a los sectores del exilio partidarios de Negrín. Existía dentro del exilio un cierto consenso en torno al rechazo del recurso a la violencia y la lucha armada, estrategia que a partir de este momento también fue progresivamente abandonando el PCE.

La postura del PCE, a través de la Junta Suprema de Unidad Nacional (JSUN), a lo largo de 1943 y 1944 fue ampliamente contestada por la posición legitimista que consideraba irrenunciable la restauración republicana como primer paso necesario para articular la vuelta a la normalidad democrática en España. Desde ARE, aprovechando la conmemoración del catorce de abril, se reivindicó en 1943 la necesidad de conformar un gobierno en el exilio, como lo tenían otros países invadidos como Bélgica, Holanda, Noruega, Polonia y Checoslovaquia, que sirviera de referente claro y mantuviese vivo el espíritu y la dignidad de la Segunda República. ${ }^{36}$

Ante el nuevo bloque político, desde fuera de las organizaciones políticas surgió una iniciativa promovida por la Unión de Profesores Universitarios Españoles Emigrados, muy influida por la cultura institucionista, que convocó en la Universidad de La Habana una reunión de profesores universitarios españoles en el exilio para octubre de ese mismo año. ${ }^{37}$ Los objetivos de esta iniciativa fueron varios. En primer

\footnotetext{
35 «Creación de la Junta Suprema de Unión Nacional, manifiesto y programa de la Junta» fechado en Madrid en septiembre de 1943. Se conserva copia en el Archivo de Amaro del Rosal 357-3, FPI, p. 20.

36 "A los españoles, manifiesto de ARE de 14 de abril de 1943». Conservado en el archivo de Manuel Albar Catalán, 161-14, Fundación Pablo Iglesias.

${ }_{37}$ Jorge de Hoyos Puente, ;Viva la inteligencia! El legado de la cultura institucionista en el exilio republicano de 1939 (Madrid: Biblioteca Nueva, 2016): 107-122.
} 
lugar, realizar una convocatoria, sin exclusiones por razones políticas, de aquellos académicos que se habían visto obligados a exiliarse por su disconformidad con la dictadura que les había desposeído de sus cátedras. A ese respecto, hay que señalar que a la reunión fue invitado Juan Negrín, no en calidad de político sino como catedrático de fisiología. En segundo lugar, el encuentro tenía como pretensión central elaborar un programa técnico sobre la situación de España, un diagnóstico que pudiera servir de base para un futuro trabajo de reconstrucción. En tercer lugar, con la promulgación de la Declaración de La Habana, los académicos españoles proclamaron la firme adhesión de la España democrática a los principios de la Carta del Atlántico, suscrita en agosto de 1941 por Gran Bretaña y Estados Unidos y base para la formulación de las futuras Naciones Unidas. Sobre el fondo de este acuerdo, los profesores universitarios reivindicaron el derecho de los demócratas españoles a ser asistidos por las potencias aliadas para derrocar al franquismo y reinstaurar las libertades perdidas. Finalmente, la reunión instó a promover la unidad de acción del exilio a través de una junta unitaria e integradora, que sirviese de interlocutor único con las potencias aliadas. ${ }^{38}$ Esta iniciativa, de la que participaron activamente figuras como José Giral, Fernando de los Ríos, Cándido Bolívar, Joaquín Xirau, María Zambrano, Mariano Ruiz Funes o Augusto Pittaluga entre otros, tuvo prácticamente una respuesta inmediata: la constitución un mes después de la Junta Española de Liberación.

La Junta Española de Liberación, la JEL, nació de un pacto entre tres sectores bien diferentes: el republicanismo legitimista constituido en torno a ARE, capitaneado por Diego Martínez Barrio, el socialismo moderado controlado por Indalecio Prieto y el nacionalismo catalán. ${ }^{39}$ Los objetivos de la Junta eran la defensa de la continuidad de las instituciones republicanas, representadas por las Cortes, que debían ser convocadas fuera de España para solucionar la situación vacante de la presidencia de la República y, más tarde, ratificar un nuevo gobierno en el exilio. Las razones que llevaron a estos grupos a forjar este acuerdo fueron las siguientes: para los republicanos, su tesis legitimista salía refor-

\footnotetext{
${ }_{38}$ VV.AA., Libro de la primera reunión de profesores universitarios españoles emigrados (La Habana: Talleres tipográficos La Mercantil, 1944).

${ }^{39} \mathrm{El}$ acuerdo fue firmado el 25 de noviembre de 1943 por Izquierda Republicana, Unión Republicana, el Círculo Pablo Iglesias, Ezquerra Republicana de Cataluña y Acción Republicana Catalana.
} 
zada y la posición de su líder, Martínez Barrio, pasaría a jugar un papel preponderante como futuro presidente interino de la República; para los socialistas seguidores de Prieto este acuerdo suponía una alianza táctica que permitiría arrinconar definitivamente a Negrín, y recuperar el protagonismo y el prestigio perdidos tras la intervención de la JARE; para el nacionalismo catalán permitiría explorar una vía posible que, además, garantizaba la vigencia del gobierno catalán y su estatuto de autonomía.

La JEL cumplió solo parcialmente con el llamamiento de la declaración de La Habana, en la medida en que estableció exclusiones que pronto fueron contestadas por amplios sectores del exilio y también por Negrín desde Londres por diferentes razones. Negrín rechazó la política de juntas, tanto la de la JEL como la de la JSUN, dos estrategias a su juicio erradas que confundían más de lo que ayudaban a mantener un diálogo fluido con las potencias aliadas, un diálogo clave, que solo podía ser realizado por el último gobierno de la Segunda República, representado por él. ${ }^{40}$ Consciente de su cada vez más debilitada posición, Negrín intensificó contactos diplomáticos con las potencias aliadas y reactivó junto con los ministros que todavía le eran fieles las redes del negrinismo. ${ }^{41}$

A pesar de contar con estos elementos de oposición, la JEL desarrolló una importante labor política, concentrando sus esfuerzos en mejorar las vías de interlocución con los principales líderes de las potencias aliadas con la intención de poner en valor la existencia de una oposición organizada y mayoritaria en el exilio que no estaba vinculada con el comunismo, estrategia que desarrollaron, no sin fricciones internas, durante todo 1944. Con todo, los intentos de influir colisionaban contra síntomas preocupantes. El 24 mayo de ese mismo año, el primer ministro británico Winston Churchill manifestó en la Cámara de los Comunes su posición contraria a inmiscuirse en asuntos de España, que solo podían desestabilizar esa región del mediterráneo. ${ }^{42}$ Este dis-

\footnotetext{
${ }^{40}$ Michael Alpert, «Don Juan Negrín en Londres, 1940-1956», en La oposición al régimen de Franco, eds. Javier Tusell, Alicia Alted y Abdón Mateos (Madrid: UNED, 1990): 90.

${ }^{41}$ Moradiellos, Negrín, 533 y sig; Jorge de Hoyos Puente, «La evolución del negrinismo en el exilio republicano en México», Historia y Política: ideas, procesos y movimientos sociales 36 (2016): 313337.

42 María del Rosario Alonso García, Historia, diplomacia y propaganda de las instituciones de la República Española en el exilio (1945-1962) (Madrid: Fundación Universitaria Española, 2004): 37.
} 
curso, producido un mes después del acuerdo entre Franco y las potencias aliadas para reducir la exportación de wolframio por parte de España a la Alemania nazi, marcó la actitud de Gran Bretaña para el futuro. Por el contrario, la liberación de París en agosto, con la participación protagónica de exiliados españoles, insufló esperanza y optimismo en el colectivo.

La creación de la JEL supuso la desaparición de ARE y, por tanto, la reactivación de Unión Republicana y de Izquierda Republicana a través de la convocatoria de asambleas en junio y en agosto respectivamente, con la intención de estar preparados para la convocatoria de Cortes. A esas alturas, hasta un anarcosindicalista como Juan García Oliver planteaba la necesidad de reunir a los diputados en el exilio para conformar un gobierno de concentración. ${ }^{43}$

Martínez Barrio realizó, a finales de 1944, un primer intento para conseguir las condiciones necesarias para realizar una convocatoria formal de las últimas Cortes republicanas en la ciudad de México. En enero de 1945 se celebró una primera reunión simbólica donde se homenajeó a los diputados muertos durante la guerra. Martínez Barrio abandonó la presidencia de la JEL para concentrarse en la presidencia de las Cortes. La actividad institucional se vio frenada por la convocatoria de la Conferencia de San Francisco a partir de abril de aquel año, donde se establecerían las bases de reconstrucción de la política mundial y a la que los exiliados españoles, nuevamente divididos, dedicaron todos sus esfuerzos de persuasión. La JEL elaboró un extenso informe para mostrar a las potencias aliadas las múltiples conexiones desde antes del inicio de la guerra civil española de Franco y sus seguidores con las potencias del eje. ${ }^{44}$ Negrín realizó una gira con actos multitudinarios en México y Toulouse para mostrar la fuerza de su causa antes de trasladarse a Estados Unidos para asistir a la Conferencia de San Francisco. Junto a Negrín, asistieron su ministro de Estado, Julio Álvarez del Vayo, y el Lehendakari José Antonio Aguirre. A su vez, la delegación de la JEL estuvo compuesta por Indalecio Prieto, Félix Gordón Ordás, José Giral y Antonio M. ${ }^{a}$ Sbert. Ambas delegaciones trabajaron para propiciar

\footnotetext{
43 Juan García Oliver, El eco de los pasos (Barcelona: Ruedo Ibérico, 1978): 584 y sig.

${ }_{44}$ Véase «La Junta Española de Liberación ante la Conferencia de San Francisco de California» en el Archivo de Carlos Esplá, 6.1/5215-b. Centro Documental de la Memoria Histórica, Salamanca.
} 
que las potencias aliadas rompieran relaciones diplomáticas con la dictadura franquista y propiciaran el reconocimiento de un gobierno en el exilio. Con la ayuda del embajador mexicano Luis Quintanilla, que defendió oficialmente su causa, alcanzaron un primer logro como fue bloquear la entrada de España en las Naciones Unidas, lo que el exilio en su conjunto interpretó como un primer éxito. ${ }^{45}$

Finalizada la cumbre, el siguiente paso era una nueva reunión de las Cortes, convocadas esta vez con el consenso de los grupos políticos y los requisitos legales necesarios para agosto en la ciudad de México. En aquella reunión solemne se dilucidó la pugna entre la coalición formada por los republicanos liberales, los socialdemócratas y el nacionalismo catalán, frente a Negrín y sus partidarios. ${ }^{46}$ A pesar de estar en minoría, Negrín aceptó asistir a la reunión a condición de que se le reconociera su condición de jefe de gobierno, petición que fue aceptada por sus detractores. En un clima de optimismo ante la posibilidad de un pronto regreso a España, las Cortes constituidas por noventa y siete diputados y con la adhesión expresa de cuarenta más que no pudieron viajar, tomaron juramento como presidente interino de la República a Diego Martínez Barrio, a quien Negrín presentó, como era preceptivo, su dimisión formal.

Según testimonio de Juan Marichal, Negrín tenía una baza importante bajo la manga. Si conseguía ser ratificado por las Cortes como presidente del gobierno, la Francia de De Gaulle reconocería el gobierno republicano como el legítimo de España, lo que suponía un espaldarazo importante a las pretensiones del exilio. De Gaulle y Negrín habían mantenido contactos y cercanía en su común exilio en Londres. Un grupo de jóvenes negrinistas, entre los que se encontraba el propio

\footnotetext{
45 José María del Valle, Las instituciones de la República española en exilio (París: Ruedo Ibérico, 1976): 102 y sig.

${ }^{46}$ Poco antes de la reunión de las Cortes, la Oficina de Investigaciones políticas y sociales del gobierno mexicano emitió un informe, a instancia de sus superiores, sobre el estado de las relaciones de las organizaciones políticas de los republicanos españoles. El informe señala el origen de las disputas en el pleito entre Prieto y Negrín enconado durante años, pero hace hincapié en la escasa peligrosidad que presenta esa fricción para el gobierno mexicano que, en todo caso, tendrá que disolver alguna pelea a puñetazos en alguno de los cafés frecuentados por los refugiados. Véase «Informe sobre investigación practicada acerca del ambiente político que prevalece entre los republicanos españoles», fechado en México a 31 de julio de 1945. Fondo de Investigaciones Políticas y Sociales, vol. 70, exp. 4, folios 123-134. Archivo General de la Nación de México.
} 
Marichal, trataron de convencer a Martínez Barrio de la imperiosa necesidad que suponía ratificar a Negrín, a lo que el político sevillano se negó. ${ }^{47}$ Martínez Barrio eligió al ex-presidente José Giral, que volvía a la arena política dispuesto a trabajar por el entendimiento de todos. Pese a los intentos de Giral de contar con Negrín como ministro de Estado éste se negó, apartándose de la lucha política para dejar trabajar a un nuevo gobierno al que reconoció toda legitimidad. Fueron sus partidarios quienes protestaron ante lo que consideraban un gran error político. Con el fracaso de Negrín y su aceptación del resultado, perdían su razón política de existir. El sometimiento de Negrín representaba también la derrota del obrerismo marxista articulado en torno al PCE, que finalmente había apostado sus posibilidades de influencia política en aquel futuro regreso que consideraba inminente. Con el fracaso de $\mathrm{Ne}-$ grín y el triunfo de las tesis del liberalismo democrático los comunistas debían reformular su estrategia.

Giral consiguió, tras muchos esfuerzos y meses de negociación, nombrar un gobierno compuesto por representantes de las principales organizaciones políticas y sindicales. De este modo, creía garantizarse la estabilidad y el reconocimiento a sus gestiones. ${ }^{48}$ Finalmente, en noviembre de 1945 pudo presentarse de nuevo ante las Cortes para presentar su amplio programa de gobierno que fijaba la estrategia a desarrollar para regresar a España y para reconstruir el país. ${ }^{49} \mathrm{El}$ primer gobierno Giral en el exilio pensaba en la reconstrucción del país y, para ello, se dotó de un amplio personal técnico pero, motivado por un clima de optimismo generalizado, dedicaron poco tiempo a pensar el paso previo, cómo iban a regresar a España. El más consciente de esta situación fue Prieto, que en su intervención en el pleno, en nombre de la mi-

\footnotetext{
47 Juan Marichal, «Juan Negrín y la continuidad de la II República», en La oposición al régimen de Franco, eds. Javier Tusell, Alicia Alted y Abdón Mateos (Madrid: UNED, 1990):71.

48 José Giral contó entre sus ministros con los socialistas Fernando de los Ríos y Trifón Gómez, éste en representación de la UGT, por Izquierda Republicana Álvaro de Albornoz y Augusto Barcia, por Unión Republicana Manuel Torres Campañá, por ERC Miguel Santaló, por Acción Republicana Catalana Luís Nicolau D’Olwer, por CNT José Expósito y Horacio Martínez, por el PNV Manuel de Irujo y, como independientes, el general Juan Hernández Saravia y Ángel Ossorio y Gallardo (Josep Sánchez Cervelló, La Segunda República en el exilio (Barcelona: Planeta, 2011): 455).

${ }^{49}$ El discurso de José Giral puede consultarse en el Boletín de Cortes y también en el apéndice documental de la obra de Javier Rubio, La emigración de la guerra civil, 1936-1939 (Madrid: Editorial San Martín, 1977): 1004 y sig.
} 
noría socialista, manifestó que el discurso de Giral estaba alejado de la realidad. ${ }^{50}$

Los primeros meses del gobierno Giral fueron productivos. En primer lugar, México reanudó relaciones con su gobierno devolviendo la embajada y los recursos económicos incautados a la JARE en 1942. Además de México, su gobierno fue reconocido por Guatemala, Panamá, Venezuela, Polonia, Yugoslavia, Rumania, Checoslovaquia, Hungría, Albania y Bulgaria. ${ }^{51}$ También la salida de Churchill del gobierno británico y su sustitución por los laboristas presentaba un escenario más propicio. En febrero de 1946 el gobierno republicano en el exilio consiguió la autorización del gobierno francés para trasladar su sede a París, más cerca de España. El cuatro de marzo se publicaba la nota tripartita de los gobiernos de Estados Unidos, Gran Bretaña y Francia que declaraban que España no podía mantener relaciones cordiales con esos países mientras sus ciudadanos no pudieran elegir libremente su gobierno. Sin embargo, los tres países declararon que se trataba de una situación interna de los españoles y que sus gobiernos se abstendrían de intervenir. ${ }^{52}$ De este modo, las potencias aliadas marcaban hasta dónde estaban dispuestas a llegar y, también de esta forma, el propio destino de España.

Giral, en un intento por disponer de un gobierno más representativo nombró tres nuevos ministros sin cartera, el galleguista Castelao, el republicano conservador Rafael Sánchez Guerra y el más polémico, el comunista Santiago Carrillo. Para Indalecio Prieto aquella decisión, la inclusión de los comunistas, supuso la ruptura total con el gobierno al que consideraba, «además de ineficaz, un grave estorbo en las soluciones posibles del problema español». ${ }^{53}$ A partir de ahí, el socialismo, organizado en torno a Prieto, articuló su propia estrategia política, basada en la defensa de una transición tutelada por un gobierno de concentración que estabilizase la situación inmediata para dar paso más adelante a un plebiscito. Prieto y sus seguidores sacrificaban definitivamente el

\footnotetext{
${ }^{50}$ Su discurso está recogido íntegramente en el Boletín de Cortes de 8 de noviembre de 1945.

${ }^{51}$ Sonsoles Cabeza Sánchez-Albornoz, Historia política de la Segunda República en el exilio (Madrid: Fundación Universitaria Española, 1997): 53.

52 Casilda Güell, Las potencias internacionales ante la dictadura española (1944-1950) (Barcelona: Aresta, 2009): 49.

${ }^{53}$ Así lo dice Prieto por carta el 24 de marzo de 1946. Véase «Una carta de Indalecio Prieto» Fondo México 87-1 Fundación Universitaria Española.
} 
legitimismo republicano en aras de trabajar por conseguir un mayor número de adhesiones mirando hacia los monárquicos, pero también y fundamentalmente, pensando en la posibilidad de contar con un mayor reconocimiento internacional. Para poder defender su proyecto, Prieto necesitaba trasladarse personalmente a Francia con vistas a afianzar su control de la Ejecutiva socialista en Toulouse. En ese sentido, cabe señalar que se empleó a fondo consiguiendo, en primer lugar, la dimisión de Giral tras forzar que los ministros socialistas abandonasen el gobierno. La determinación de controlar el socialismo en el exilio llevó a declarar la expulsión del PSOE y de la UGT a destacados dirigentes partidarios de Negrín y a él mismo. Así, Juan Negrín, Ramón Lamoneda, Ramón González Peña, Julio Álvarez del Vayo, Amaro del Rosal, Matilde de la Torre o Max Aub, entre otros, fueron expulsados, decisión que no reconocieron. También entre los anarcosindicalistas hubo nuevas fracturas, derivadas de la incorporación de dos ministros de la CNT al gobierno Giral. El panorama volvía a ser desolador.

\section{7-1950 DEL COLAPSO A LA ESPERA: LOS AÑOS DE LA LARGA FRUSTRACIÓN}

El fracaso del gobierno de la «esperanza» presidido por José Giral en febrero de 1947 evidenció varias cuestiones. En primer lugar, la persistencia de las divisiones dentro del exilio y la incapacidad de mantener alianzas duraderas. La decisión de Indalecio Prieto y sus seguidores de forzar la salida del gobierno de los ministros socialistas produjo su caída. En segundo lugar, los logros parciales obtenidos con las potencias internacionales mostraban al mismo tiempo sus limitaciones, marcados por la firme decisión de no intervenir en los asuntos internos de España. Finalmente, esta actitud compartida por parte de Estados Unidos, Gran Bretaña y la Unión Soviética ponía de manifiesto una realidad dolorosa: sin asistencia internacional, el gobierno de la República en el exilio carecía de una estrategia viable y de medios materiales para acabar con la dictadura franquista.

El contexto internacional no pudo ser más desfavorable para la causa republicana. ${ }^{54}$ Con el inicio de hostilidades entre el mundo capita-

\footnotetext{
${ }^{54}$ Miguel Ángel Yuste de Paz, La II República española en el exilio en los inicios de la guerra fría (1945-1951) (Madrid: Fundación Universitaria Española, 2005).
} 
lista y el socialista, la formulación de la teoría del telón de acero y el establecimiento de la política de bloques, la coyuntura parecía poco propicia para intervenir en España, donde la dictadura había consolidado su situación y había marcado distancias con las potencias del eje, explotando su posición estratégica en el mediterráneo. Las potencias occidentales se mostraron contrarias a desestabilizar la región con una intervención sin garantías.

Ante ese estado de cosas, Martínez Barrio trató de parar el alejamiento del PSOE ofreciendo el gobierno al secretario general de este partido, Rodolfo Llopis, un socialista que, sin romper con Prieto, mantenía todavía la fe en la vigencia de las instituciones republicanas. Llopis formó un efímero gobierno; sin embargo, Prieto se impuso en los órganos de dirección del PSOE en julio causando la renuncia de Llopis a la presidencia del gobierno. ${ }^{55} \mathrm{~A}$ partir de entonces, el gobierno en el exilio quedó en manos de dirigentes procedentes de los partidos republicanos, como Álvaro de Albornoz, que lo presidió hasta 1951, afirmando un republicanismo irrenunciable. Mientras tanto y tras su victoria frente a Llopis, Prieto y sus seguidores desplegaban las negociaciones con los monárquicos partidarios de Juan de Borbón. Para el grupo de Prieto la única manera de conseguir apoyo internacional era apostar por cumplir las condiciones que establecía la nota tripartita, permitir un plebiscito para elegir la forma de gobierno y, para ello, convencer a las potencias solo podía ser viable contando con los monárquicos. ${ }^{56}$ Los monárquicos jugaban con dos barajas, acercándose al PSOE sin comprometerse, para forzar a Franco a una salida pactada del poder restaurando la monarquía. ${ }^{57}$ Para reforzar el peso de la estrategia de Prieto, el III Congreso del PSOE en el exilio, celebrado en Toulouse en febrero de 1948, le nombró presidente del partido. Los motivos del fracaso de estas negociaciones son conocidos. Juan de Borbón visitó en agosto de ese

\footnotetext{
55 José Carlos Gibaja, «El PSOE, 1939-1951: reconstrucción interna y fracaso político», en La oposición al régimen de Franco, eds. Javier Tusell, Alicia Alted y Abdón Mateos (Madrid: UNED, 1990), 193-209; Sánchez Cervelló, La Segunda República en el exilio, 99-117.

${ }^{56}$ Carta de Indalecio Prieto a Fernando de los Ríos, México 12 de enero de 1948, reproducida en Octavio Ruiz-Manjón (ed.), Indalecio Prieto-Fernando de los Ríos, Epistolario 1924-1948 (Madrid: Centro de Estudios Políticos y Constitucionales, 2010), 202-208.

${ }^{57}$ Luis Carlos Hernando, «Buscando el compromiso: la negociación del pacto de San Juan de Luz», Espacio, Tiempo y Forma Serie V, no. 18 (2006): 225-244; Luis Carlos Hernando, El PSOE y la monarquí. De la posguerra a la Transición (Madrid: Eneida, 2013).
} 
año el yate Azor para entrevistarte con Franco y fijar los términos de su acuerdo, despreciando la vía ofrecida por Prieto. Para finales de 1948 todas las vías posibles se habían agotado. Los peores augurios se confirmaban, el exilio sería largo. Comenzaban los años de la larga espera.

Las instituciones republicanas en el exilio quedaron en manos de los republicanos legitimistas. A partir de ese momento, su papel se convirtió en un reducto simbólico al que el grueso de los exiliados comenzó a dejar de lado. En 1949 las penurias económicas lastraron el mantenimiento de su actividad, centrada en los primeros años cincuenta en denunciar el progresivo acercamiento de los Estados Unidos a la dictadura franquista, convertida en un fiel aliado del anticomunismo imperante. ${ }^{58}$ Ese acercamiento, que culminaría con los acuerdos bilaterales de 1953 y el posterior ingreso de España en la ONU, terminó de minar cualquier esperanza de cambio. ${ }^{59}$ También el PCE cambió notablemente su estrategia en 1948, después de la trascendental reunión que mantuvieron en septiembre en Moscú Dolores Ibárruri, Santiago Carrillo y Francisco Antón con Josef Stalin. El líder soviético mostró una vez más su desinterés por la actividad institucional de la República en el exilio, a la que la URSS no reconoció. El PCE apostó por abandonar definitivamente la lucha armada y concentrarse en la actividad clandestina en el interior de España.

\section{A MODO DE CONCLUSIÓN: CLAVES PARA ENTENDER EL EXILIO EN LOS AÑOS CUARENTA}

Este breve recorrido por la historia política del exilio republicano en los años cuarenta tiene como principal objetivo tratar de escudriñar las razones que impidieron formular una alternativa unitaria de oposición al franquismo desde fuera de España. Tradicionalmente se han explotado las razones personales, los enfrentamientos surgidos durante la Segunda República y especialmente en la gestión de la Guerra Civil. Sin embargo, nuestra explicación trata de buscar sus moti-

\footnotetext{
${ }^{58}$ Véase el comunicado de «la República Española a la opinión internacional» de 9 de noviembre de 1950, firmado por Diego Martínez Barrio como presidente de la República y Álvaro de Albornoz como Presidente del Consejo de ministros. Fondo México 87-2, Fundación Universitaria Española.

${ }^{59}$ Sonsoles Cabeza Sánchez-Albornoz, «Posición de la República española en el exilio ante el ingreso de España en la ONU», Cuadernos de Historia Contemporánea 17 (1995): 147-168.
} 
vos más allá de este razonamiento. Las disputas y los desencuentros surgieron por la existencia de visiones contrapuestas, proyectos antagónicos que, en un contexto de exilio, vivieron un proceso de radicalización discursiva que frustraron cualquier posibilidad de acuerdo. Eran proyectos políticos que venían conformándose y evolucionando tiempo atrás y ya habían dado muestras de incompatibilidad mutua, a pesar de coincidir todos en el rechazo a un enemigo común, el franquismo. La disparidad de criterios se impuso en el terreno de las estrategias y las tácticas políticas cortocircuitando cualquier posibilidad de establecer sinergias y acuerdos en un tiempo de profunda inestabilidad e incertidumbre.

Sin duda, este estado de cosas aumentó la profunda rabia y frustración que vivieron muchos exiliados tras la derrota republicana. Para los más veteranos, el exilio resultó una pesada losa que se prolongó en el tiempo hasta su muerte. Para los más jóvenes, el exilio abrió nuevos horizontes, siendo un sector minoritario el que mantuvo la vinculación partidista en el exilio. Sus lugares de acogida se convirtieron a la larga en sus nuevos hogares, recordando e idealizando la España perdida o secuestrada por el franquismo. Progresivamente, las afiliaciones a las organizaciones políticas fueron perdiendo importancia, aunque sin desaparecer del todo. Hubo muchas razones para esta desconexión. En primer lugar, una cierta sensación de desamparo generada en los primeros momentos del exilio, donde se evidenció la brecha entre cúpulas dirigentes, enfrascadas en sus disputas, y las masas de militantes y simpatizantes, centradas en sobrevivir en difíciles circunstancias materiales. En segundo lugar, una cierta perplejidad ante la virulencia de las críticas y los debates internos que generaron cierto hastío. Finalmente, la toma de conciencia, con el devenir de los acontecimientos, acerca de la inutilidad de las acciones y estrategias desplegadas.

Los exiliados buscaron nuevos espacios de sociabilidad, menos rígidos ideológicamente, para mantener su vinculación colectiva y sus señas de identidad. A pesar de las profundas diferencias existentes, se fueron construyendo ciertos consensos en torno a la idealización de la Segunda República como paradigma del «paraíso perdido». Con los años, lo político fue perdiendo contenido programático específico, conformando nuevas identidades que convivieron con dificultad con las 
organizaciones políticas que vivieron un proceso de fosilización discursiva, favorecido por la distancia y el desconocimiento de la propia evolución que se estaba produciendo en el interior de España.

\section{Nota sobre el autor}

Jorge de Hoyos Puente es Licenciado y Doctor en Historia Contemporánea por la Universidad de Cantabria. Desde 2014 trabaja en el Departamento de Historia Contemporánea en la UNED. Ha sido Visiting Scholar en la Universidad de Columbia en New York y en el Centro de Estudios Históricos de El Colegio de México en 2012 y 2013. Desde 2015 es Secretario General del Centro de Estudios de Migraciones y Exilios de la UNED (CEME). Especialista en el exilio republicano de 1939, es autor de dos libros, La utopía del regreso, Proyectos de Estado y sueños de nación en el exilio republicano en México (México, El Colegio de México, 2012) y ¡Viva la inteligencia!, el legado de la cultura institucionista en el exilio republicano (Madrid, Biblioteca Nueva, 2016), editor de dos libros, así como autor de más de cuarenta contribuciones en revistas indexadas y libros colectivos. Ha sido ponente invitado en más de cuarenta encuentros científicos internacionales en EEUU, México, Argentina, Chile, Uruguay, Francia, Portugal y España, así como profesor invitado en las Universidades de Aguascalientes (México), La Plata (Argentina) y la MGIMO (Moscú).

\section{REFERENCIAS}

Adámez Castro, Guadalupe. Gritos de papel. Las cartas de súplica del exilio español. Granada: Comares, 2017.

Alía Miranda, Francisco. La agonía de la República. El final de la guerra civil española (1938-1939). Barcelona: Crítica, 2015.

Alonso García, María del Rosario. Historia, diplomacia y propaganda de las instituciones de la República Española en el exilio (1945-1962). Madrid: Fundación Universitaria Española, 2004.

Alpert, Michael. «Don Juan Negrín en Londres, 1940-1956». En La oposición al régimen de Franco, editado por Javier Tusell, Alicia Alted y Abdón Mateos, 79-90. Madrid: UNED, 1990.

Alted Vigil, Alicia. La voz de los vencidos. El exilio republicano de 1939. Madrid: Aguilar, 2005. 
Alted, Alicia y Lucienne Domergue. La cultura del exilio anarcosindicalista español en el sur de Francia. Madrid: ediciones cinca, 2012.

Angosto, Pedro Luis. La República en México, con plomo en las alas, 1939-1945. Sevilla: Renacimiento, 2009.

Bahamonde, Ángel. Madrid 1939. La conjura del coronel Casado. Madrid: Cátedra, 2014.

Botella Pastor, Virgilio. Entre memorias, las finanzas del gobierno republicano español en el exilio. Sevilla: Biblioteca del Exilio, 2002.

Cabeza Sánchez-Albornoz, Sonsoles. «Posición de la República española en el exilio ante el ingreso de España en la ONU». Cuadernos de Historia Contemporánea 17 (1995): 147-168.

Cabeza Sánchez-Albornoz, Sonsoles. Historia política de la Segunda República en el exilio. Madrid: Fundación Universitaria Española, 1997.

Cabezas, Octavio. Indalecio Prieto. Socialista y Español. Madrid: Algaba, 2005.

Carrión, Pablo. «La delegación del PCE en México 1939-1956, origen y límite de una voluntad de liderazgo de la oposición». Espacio, Tiempo y Forma Serie $\mathrm{V}$, no. 16 (2004): 309-336.

Cortesão, Armando, Luis Araquistain, Manuel de Irujo y Carles Pi Sunyer. La Comunidad Ibérica de Naciones. Buenos Aires: Exin, 1945.

Duarte, Ángel. El otoño de un ideal. El republicanismo histórico español y su declive en el exilio de 1939. Madrid: Alianza Editorial, 2009.

Estévez, Xosé. ed. Antología de Galeuzca en el exilio, 1939-1960. San Sebastián: J.A. Ascunce, 1992.

Estruch, Joan. El PCE en la clandestinidad, 1939-1956. Madrid: Siglo XXI, 1982.

García Oliver, Juan. El eco de los pasos. Barcelona: Ruedo Ibérico, 1978.

Gaspar Celaya, Diego. La Guerra continúa. Voluntarios españoles al servicio de la Francia Libre (1940-1945). Madrid: Marcial Pons, 2015.

Gibaja, José Carlos. «El PSOE, 1939-1951: reconstrucción interna y fracaso político». En La oposición al régimen de Franco, editado por Javier Tusell, Alicia Alted y Abdón Mateos, 193-209. Madrid: UNED, 1990.

Gibaja, José Carlos. Indalecio Prieto y el socialismo español. Madrid: Editorial Pablo Iglesias, 1995.

Gracia Alonso, Francisco y Gloria Munilla. El tesoro del «Vita». La protección y el expolio del patrimonio histórico-arqueológico durante la Guerra Civil. Barcelona: Universitat de Barcelona, 2013.

Güell, Casilda. Las potencias internacionales ante la dictadura española (19441950). Barcelona: Aresta, 2009.

Heine, Hartmut. La oposición politica al franquismo. Barcelona: Crítica, 1983.

Hernando, Luis Carlos. El PSOE y la monarquía. De la posguerra a la Transición. Madrid: Eneida, 2013. 
Hernando, Luis Carlos. «Buscando el compromiso: la negociación del pacto de San Juan de Luz». Espacio, Tiempo y Forma Serie V, no. 18 (2006): 225-244. Herrerín, Ángel. La CNT durante el franquismo. Clandestinidad y exilio (19391975). Madrid: Siglo XXI, 2004.

Herrerín, Ángel. El dinero del exilio, Indalecio Prieto y las pugnas de posguerra (1939-1947). Madrid: Siglo XXI, 2007.

Hoyos Puente, Jorge de. La utopía del regreso. Proyectos de Estado y Sueños de Nación en el exilio republicano en México. México: El Colegio de México, 2012.

Hoyos Puente, Jorge de. «La evolución del negrinismo en el exilio republicano en México». Historia y Política: ideas, procesos y movimientos sociales 36 (2016): 313-337.

Hoyos Puente, Jorge de. ;Viva la inteligencia! El legado de la cultura institucionista en el exilio republicano de 1939. Madrid: Biblioteca Nueva, 2016.

Jiménez de Aberasturi, Juan Carlos. «Irujo en Londres, 1939-1945». Vasconia: Cuadernos de historia-geografía 32 (2002): 99-132.

Marichal, Juan. «Juan Negrín y la continuidad de la II República». En La oposición al régimen de Franco, editado por Javier Tusell, Alicia Alted y Abdón Mateos, 67-72. Madrid: UNED, 1990.

Mateos, Abdón (ed.). Indalecio Prieto y la política española. Madrid: Fundación Pablo Iglesias, 2008.

Mateos, Abdón. La batalla de México. Final de la Guerra Civil y ayuda a los refugiados, 1939-1945. Madrid, Alianza Editorial, 2009.

Miralles, Ricardo (ed.). Textos escogidos, Indalecio Prieto. Oviedo: Junta General del Principado de Asturias, 2002.

Miralles, Ricardo. Juan Negrín, La República en guerra. Madrid: Temas de hoy, 2003.

Monferrer, Luis. Odisea en Albión: los republicanos españoles exiliados en Gran Bretaña, 1939-1977. Madrid: Ediciones de la Torre, 2008.

Moradiellos, Enrique. Negrín, una biografía de la figura más difamada de la España del siglo xx. Barcelona: Península 2006.

Pablo, Santiago de y Ludger Mees. El péndulo patriótico, historia del Partido Nacionalista Vasco, 1895-2005. Barcelona: Crítica, 2005.

Preston, Paul. El final de la guerra. La última puñalada a la República. Barcelona: Debate, 2014.

Rosal, Amaro del. El oro del banco de España y la Historia del Vita. Barcelona: Grijalbo, 1976.

Rubio, Javier. La emigración de la guerra civil, 1936-1939. Madrid: Editorial San Martín, 1977.

Ruiz-Manjón, Octavio (ed.). Indalecio Prieto-Fernando de los Ríos, Epistolario 1924-1948. Madrid: Centro de Estudios Políticos y Constitucionales, 2010. 
Sánchez Cervelló, Josep. La Segunda República en el exilio. Barcelona: Planeta, 2011.

Valle, José María del. Las instituciones de la República española en exilio. París: Ruedo Ibérico 1976.

Velázquez, Aurelio. Empresas y finanzas del exilio. Los organismos de ayuda a los republicanos españoles en México (1939-1949). México: El Colegio de México, 2014.

Viñas, Ángel y Fernando Hernández Sánchez. El desplome de la República: la verdadera historia del fin de la Guerra Civil. Barcelona: Crítica, 2010.

VV.AA. Libro de la primera reunión de profesores universitarios españoles emigrados. La Habana: Talleres tipográficos La Mercantil, 1944.

Yuste de Paz, Miguel Ángel. La II República española en el exilio en los inicios de la guerra fría (1945-1951). Madrid: Fundación Universitaria Española, 2005. 